\title{
Relationship between roar sound characteristics and body size of Steller sea lion
}

\author{
Tae-Geon PARK*, Kohji IIDA ${ }^{1}$ and Tohru MUKaI ${ }^{1}$ \\ Cetacean Research Institute, NFRDI, Ulsan 680-050, Korea \\ ${ }^{1}$ Graduate School of Fisheries Sciences, Hokkaido University, Hakodate, Hokkaido, Japan
}

Hundreds of Steller sea lions, Eumetopias jubatus, migrate from Sakhalin and the northern Kuril Islands to Hokkaido every winter. During this migration, they may use their roaring sounds to navigate and to maintain their groups. We recorded the roars of wild Steller sea lions that had landed on reefs on the west coast of Hokkaido, and those of captive sea lions, while making video recordings. A total of 300 roars of wild sea lions and 870 roars of captive sea lions were sampled. The fundamental frequency $\left(\mathrm{F}_{0}\right)$, formant frequency $\left(F_{1}\right)$, pulse repetition rate (PRR), and duration of syllables $(T)$ were analyzed using a sonagraph. $F_{0}, F_{1}$, and PRR of the roars emitted by captive sea lions increased in the order male, female, and juvenile. By contrast, the $F_{1}$ of wild males was lower than that of females, while the $F_{0}$ and PRR of wild males and females did not differ statistically. Moreover, the $\mathrm{F}_{0}$ and $\mathrm{F}_{1}$ frequencies for captive sea lions were higher than those of wild sea lions, while PRR in captive sea lions was lower than in wild sea lions. Since there was a linear relationship between body length and the $F_{0}$ and $F_{1}$ frequencies in captive sea lions, the body length distribution of wild sea lions could be estimated from the $\mathrm{F}_{0}$ and $\mathrm{F}_{1}$ frequency distribution using a regression equation. These results roughly agree with the body length distribution derived from photographic geometry. As the volume of the oral cavity and the length of the vocal cords are generally proportional to body length, sampled roars can provide useful information about a population, such as the body length distribution and sex ratio.

Keywords: Steller sea lion, Roar sound, Body size, Acoustic characteristic

\section{Introduction}

Dolphins and whales emit click and whistle sounds underwater, and use these sounds for echolocation and communication. Pinnipeds generally do not roar while in the water (Oliver,
1978; Scronce and Ridgway, 1980; Schustreman et al., 2000), but may use their roar to identify others in breeding grounds and landing places. Although the Steller sea lion has big eyes, its vision is weak (Schustreman, 1972; Hobson, 1966; Schustreman

\footnotetext{
*Corresponding author: parktg@nfrdi.go.kr, Tel: 82-52-270-0930, Fax: 82-52-270-0913
} 
2000). Therefore, its roar sounds must perform important roles when navigating during longdistance migration and for maintaining group cohesion. The roar of the Steller sea lion is characterized by its intensity, frequency spectra and pitch pattern, and is related to its behaviors (Park et al., 2006). Can these sea lions identify sex, size, group, and family using sounds? In order to answer this question, we studied the acoustical behavior of Steller sea lions.

Every winter, hundreds of Steller sea lions migrate from Sakhalin and the northern Kuril Islands to Hokkaido. We recorded their acoustical behavior using a microphone and video camera and analyzed the relationships between the acoustic characteristics of the roar and the morphological characteristics of Steller sea lions.

\section{Materials and Methods}

\section{Recording and analyzing roar sounds}

The roars of Steller sea lions, Eumetopias jubatus, were monitored using a microphone placed near the sea lions and their behaviors were recorded with a videocassette recorder (VCR). Then, the videotapes were replayed, and the acoustic signals were analyzed using an oscilloscope, Fast Fourier Transform (FFT) analyzer, and digital sonagraph (KAY model 5500). The analysis procedure was as follows: roars were separated from ambient noise; the roar was resolved into a unit phrase; amplitude waveforms were drawn, and sonagrams produced. As the amplitude waveform and frequency spectra (analyzed using the oscilloscope and FFT analyzer) showed that the duration and dominant frequency of most roars was less than $4 \mathrm{sec}$ and $4 \mathrm{kHz}$, respectively, the analyzing range of the digital sonagraph was set from 4 to $16 \mathrm{kHz}$ in the frequency domain and 1 to $4 \mathrm{sec}$ in the time domain.
As the roars of Steller sea lions contain fundamental sounds and several harmonic sounds that continue for a few seconds at various amplitudes and frequencies, the stratified patterns were displayed on a sonagram.

In order to examine the characteristics of the roar sound, some acoustic parameters were defined and used in the experiments: the duration (T), fundamental frequency $\left(\mathrm{F}_{0}\right)$, formant frequency $\left(\mathrm{F}_{1}\right)$, and pulse repetition rate (PRR) as shown in Fig. 1. The duration $\mathrm{T}(\mathrm{sec})$ was the length of one phrase; the fundamental frequency F0 $(\mathrm{Hz})$ was the lowest

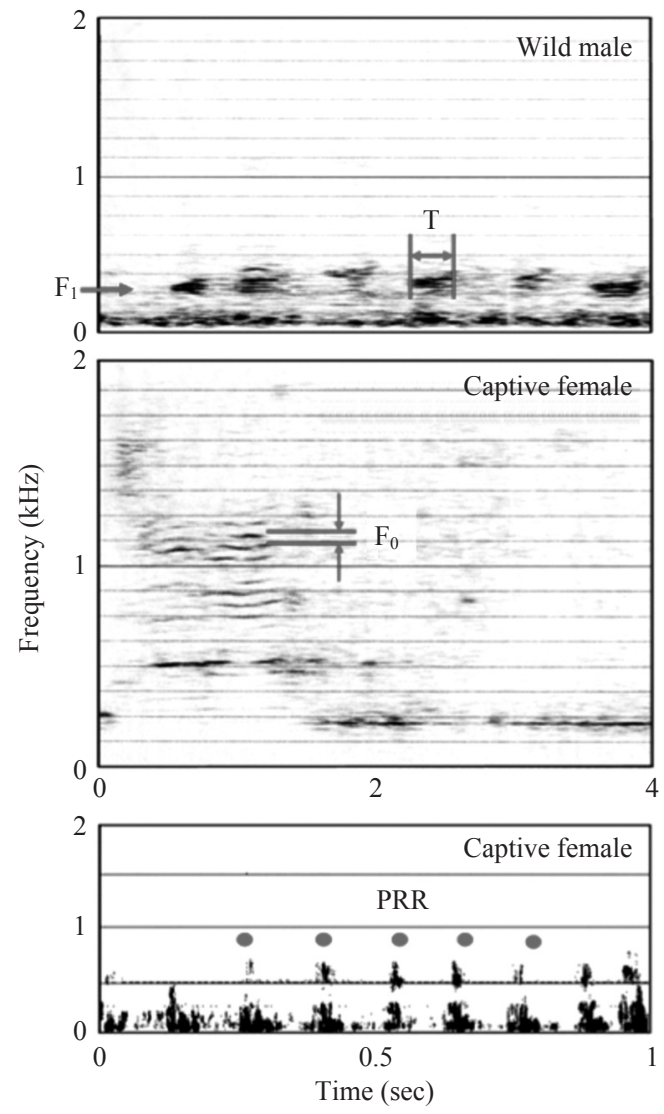

Fig. 1. Acoustic parameters of the roars of Steller sea lions.

The duration $\mathrm{T}(\mathrm{sec})$, Fundamental frequency $\mathrm{F}_{0}(\mathrm{~Hz})$, Formant frequency $\mathrm{F}_{1}(\mathrm{~Hz})$, and Pulse repetition rate PRR $(\mathrm{Hz})$ were defined by sonagrams. 
frequency component in harmonic sounds; the formant frequency $\mathrm{F}_{1}(\mathrm{~Hz})$ was the most dominant component in harmonic sounds; and the pulse repetition rate PRR $(\mathrm{Hz})$ was the cyclic frequency of amplitude waveforms of the roar sound.

In general, the fundamental frequency and PRR corresponded to the vibration frequency of the vocal cords and the formant frequency was close to the resonant frequency of the oral cavity of the animal (Kelemen, 1963).

All the roars sampled from videotapes of captive sea lions in an aquarium and wild sea lions on reefs were analyzed to obtain $T, F_{0}, F_{1}$, and PRR.

\section{Recording and analyzing the roars of captive sea lions}

The roars and behaviors of captive sea lions were observed in November 2001 at Muroran Aquarium and in October 2003 at Otaru Aquarium. There were three Steller sea lions at the Muroran Aquarium: a 23-year-old male, an 18-year-old female, and a 3-year-old male pup. A microphone and video camera were placed outside the cage and their roars and behaviors were recorded for 30 days continuously. The Otaru Aquarium kept six Steller sea lions: one male, three females, and two female pups. Their roars and behavior were recorded using a VCR for two days and the acoustic characteristics of the roar and morphological data, such as the sex, growth stage, and size, of each Steller sea lion were analyzed.

Approximately 180 roars were sampled from videotapes of the three Steller sea lions at the Muroran Aquarium. The sampled roars were analyzed using a digital sonagraph to determine the formant frequency $\left(F_{1}\right)$, fundamental frequency $\left(\mathrm{F}_{0}\right)$, pulse repetition rate (PRR), and duration $(\mathrm{T})$. Then, these data were compared with confirmed morphological data, such as the sex, growth stage, and size of each individual. In addition, 690 roars were sampled for analysis from the videotapes recorded at the Otaru Aquarium.

\section{Recording and analyzing the roars of wild sea lions}

The roars and behavior of wild sea lions on reefs near Cape Ofuyu, western Hokkaido, Japan, were observed in the early spring of 2003 and 2004. Every winter, up to 100 Steller sea lions land on Todo-Iwa Reef (“odo-Iwa"means the Steller sea lions'rock). To observe the roar and behavior of landed sea lions, a microphone and video camera (CCD camera) were placed on the reef. The VCR was powered using $12 \mathrm{~V}$ batteries and the instruments were operated remotely by radio control at a cliff $300 \mathrm{~m}$ from the reef. Continuous observations were made for five days. A distance marker was drawn on the reef in order to measure the size of the sea lions from the cliff. The videotape was replayed and the roar sounds were analyzed using a digital sonagraph, and the sex, growth stage

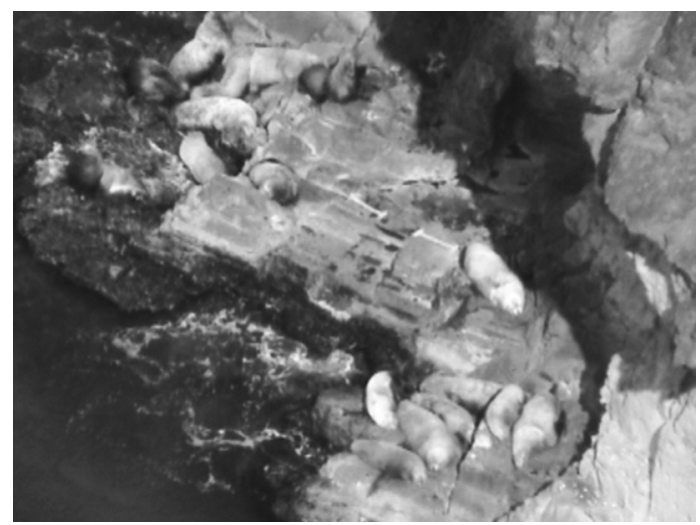

Fig. 2. Bird's-eye photograph of landed Steller sea lions on the reef taken from the cliff.

Sizes of sea lions were measured by the distance marker drawn on the reef. 
and size of the landed sea lions were measured using pictures taken from the cliff as shown in Fig.2. The relationship between the acoustic characteristics of the roar and the morphology of the wild sea lions was investigated.

On the reef at Cape Ofuyu in 2003, 63, 59 and 42 sea lions were observed on April 13, 14 and 16, respectively. In 2004, an additional 80, 51, 89, 13, 81, 67 and 80 sea lions were observed on March 4,
$5,6,7,8,9$ and 10 , respectively. When hunting boats approached the reef to kill sea lions on March 7 , many of the sea lions dispersed.

\section{Results}

Acoustic characteristics of the roars of captive sea lions

The right column of Fig. 3 shows the frequency distributions of the acoustic parameters $T, F_{1}, F_{0}$,
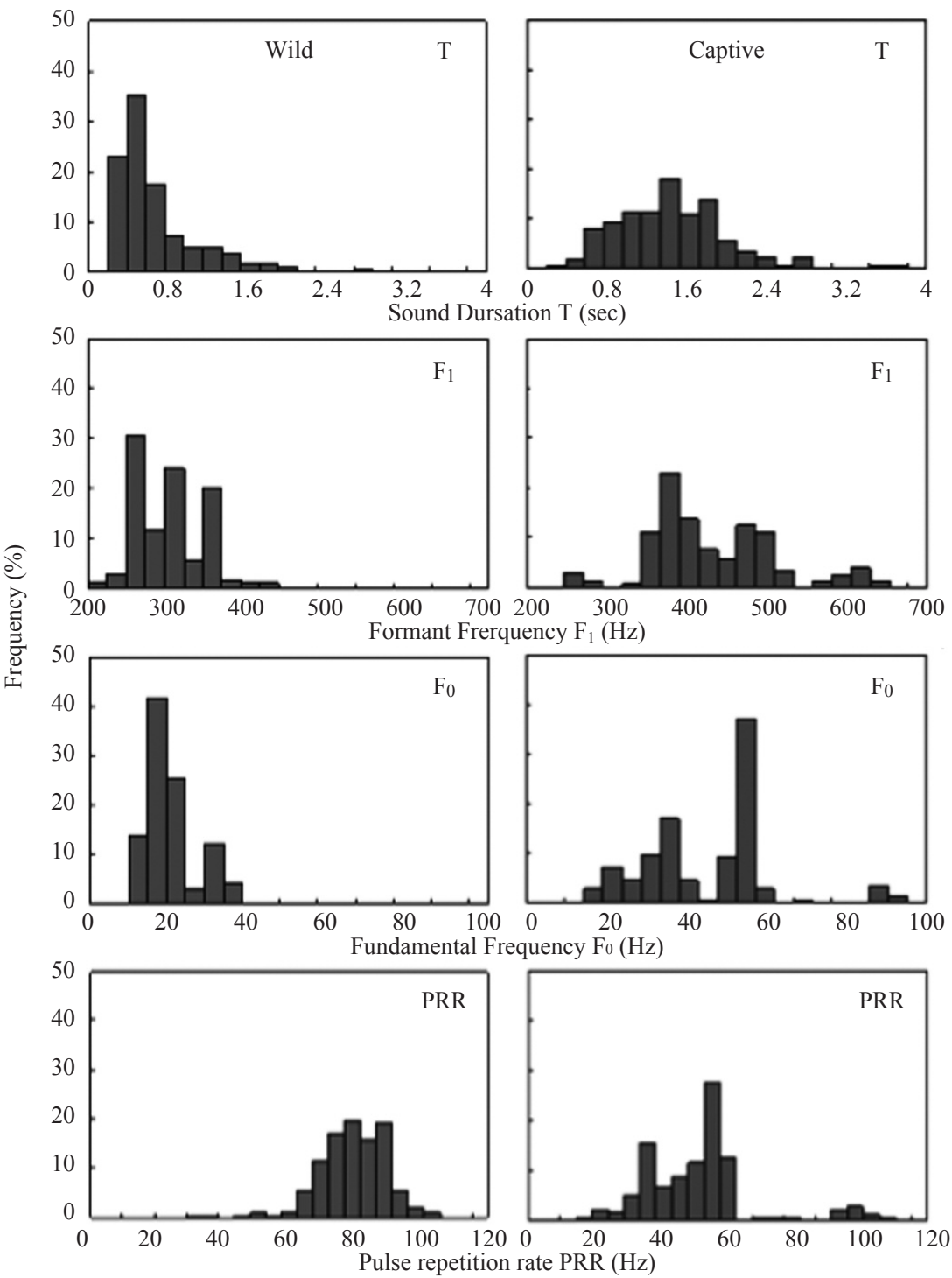

Fig. 3. Comparison of acoustic parameters of roars between wild and captive sea lions. 
and PRR. $F_{1}$ ranged from 357 to $570 \mathrm{~Hz}$; $F_{0}$ ranged from 17 to $60 \mathrm{~Hz}$; PRR ranged from 9 to $50 \mathrm{~Hz}$; and $\mathrm{T}$ ranged from 0.3 to $1.7 \mathrm{~s}$. The pitch patterns on the sonagrams generally showed a flat range of frequencies. The sonagrams of roars were classified into three categories: "communication sound",

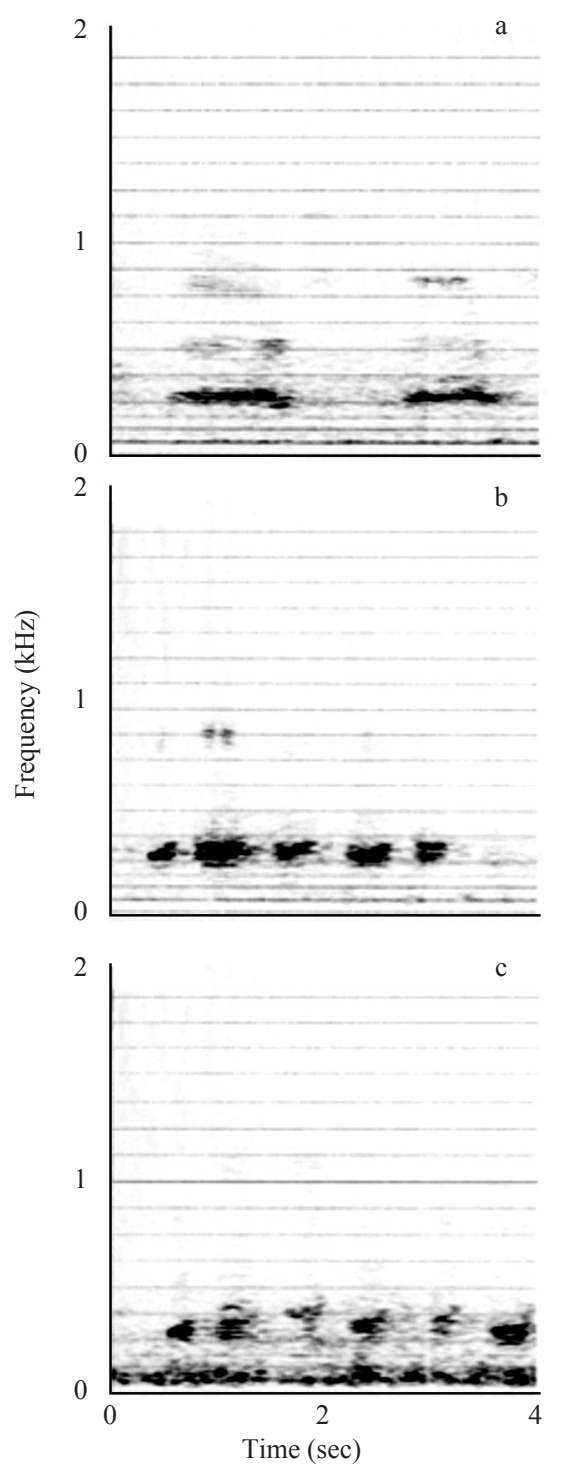

Fig. 4. Representative pitch patterns on the sonagrams of the roars of sea lions.

a: communication sound in wild male, b: wheedling sound in wild male, and c: threat sound in wild female. "wheedling sound" and "threat sound"(Evance, 1966). The communication sound was a long, flat, intermittent sound; the wheedling sound was a short, intermittent sound; and the threat sound consisted of short intermittent sounds that decreased in frequency at the end of the phrase as shown in Fig 4.

Comparing the acoustic characteristics and morphology of the sea lions, $F_{1}, F_{0}$, and PRR were higher in females than in males, and were also higher in juveniles than in adults. No significant differences in $\mathrm{T}$ were observed for sex or growth stage.

\section{Acoustic characteristics of the roars of wild sea lions}

The recorded roars of wild sea lions were analyzed using a digital sonagraph and classified into the same three categories as those of captive sea lions.

The frequency distributions of the acoustic parameters of the roars of wild sea lions are shown in the left column in Fig. 3. T ranged from 0.3 to $1.2 \mathrm{~s} ; \mathrm{F}_{1}$ ranged from 280 to $370 \mathrm{~Hz} ; \mathrm{F}_{0}$ ranged from 18 to $30 \mathrm{~Hz}$; and PRR ranged from 11 to 54 Hz. Although it was impossible to identify the individuals from photographs because there were so many sea lions on the reef, males, females, and juveniles could be discriminated using the characteristics of the roars.

Comparing the acoustic parameters of the roars of wild sea lions with the morphology of the sea lions, $F_{1}, F_{0}$, and PRR increased in the order male, female, and juvenile, as in captive sea lions. $\mathrm{T}$ did not differ significantly with sex or growth stage.

To examine the relationship between the roar and the behavior of wild sea lions, the roar sound and videotaped behavior were synchronized and 
analyzed. The wild sea lions normally emit communication sounds, produce threat sounds when quarrelling or scrambling for a place or when obstructing the landing of other sea lions, and produce a wheedling sound when relaxing.

\section{Discussion}

It was confirmed that $F_{0}, F_{1}$, and PRR were inversely proportional to the size of the sea lions, in both captive and wild sea lions, as shown in Table 1. The table shows that $\mathrm{F}_{0}, \mathrm{~F}_{1}$, and PRR were higher in females than in males, and that $\mathrm{F}_{0}, \mathrm{~F}_{1}$, and PRR were higher in juveniles than in adults. Moreover, the frequencies were generally higher in captive sea lions than in wild sea lions. By contrast, although there were no remarkable differences in $\mathrm{T}$ for sex and stage, it tended to be shorter in wild sea lions than in captive sea lions.

There was a significant linear relationship among the acoustic parameters $\mathrm{F}_{0}, \mathrm{~F}_{1}$, and PRR (Fig. 5). Generally, the fundamental frequency of a voice represents the vibrating frequency of the vocal cords and the formant frequency depends on the resonant frequency of the oral cavity for landed wild sea lions, as in human beings. Since PRR may be considered as the frequency of the cyclic amplitude waveform of oral sound, it would be close to the vibrating frequency of the vocal cords. In the other words, the length of the vocal cords and the volume of the oral cavity of Steller sea lions increases with their size, as in humans, so that the roar frequency of juveniles is higher than that of adults, and the roar
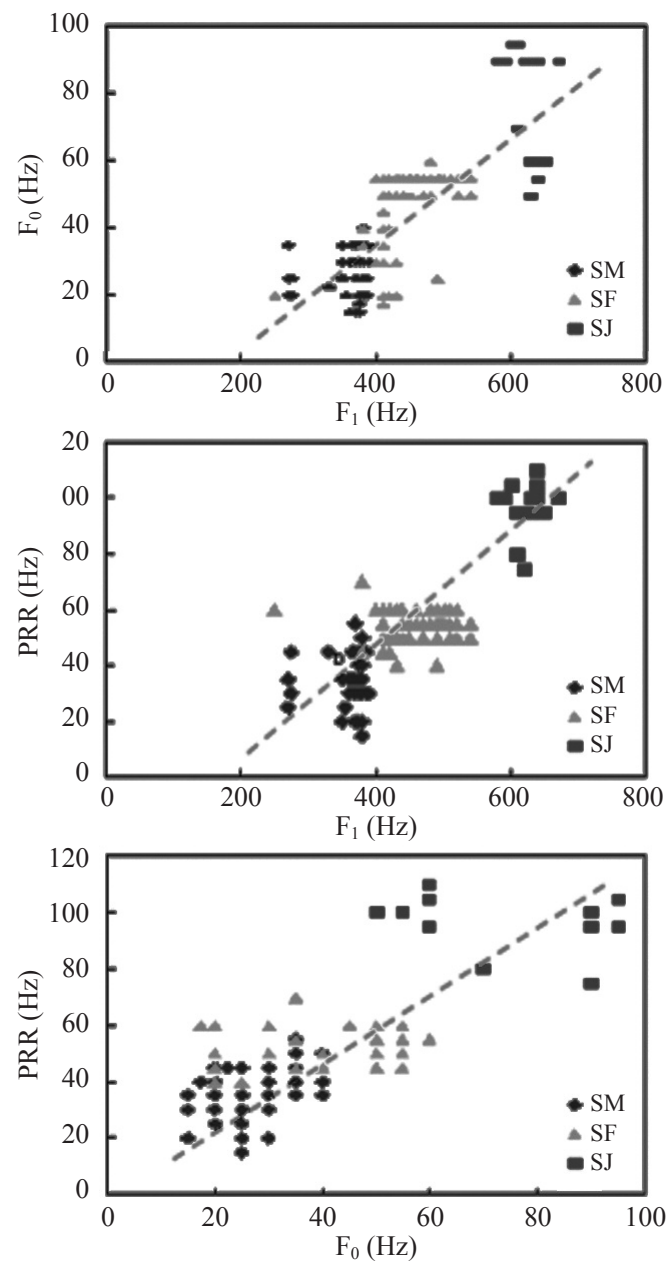

Fig. 5. Relationship among the acoustic parameters of captive sea lion's roars.

Table 1. Statistical values of acoustic parameters of roars among male and female and pup between wild and captive Steller sea lion.

\begin{tabular}{|c|c|c|c|c|c|c|c|c|c|c|}
\hline \multirow{3}{*}{ Acoustic parameters } & \multicolumn{4}{|c|}{ Wild animals } & \multicolumn{6}{|c|}{ Captive animals } \\
\hline & \multicolumn{2}{|c|}{ Male } & \multicolumn{2}{|c|}{ Female } & \multicolumn{2}{|c|}{ Male } & \multicolumn{2}{|c|}{ Female } & \multicolumn{2}{|c|}{ Pup } \\
\hline & Ave. & S.D. & Ave. & S.D. & Ave. & S.D. & Ave. & S.D. & Ave. & S.D. \\
\hline Formant Frequency $\mathrm{F}_{1}(\mathrm{~Hz})$ & 263 & 15.2 & 353 & 36.4 & 372 & 20.0 & 469 & 46.7 & 626 & 23.3 \\
\hline Fundamental Frequency $\mathrm{F}_{0}(\mathrm{~Hz})$ & 19 & 3.5 & 17 & 3.6 & 36 & 2.5 & 53 & 4.9 & 76 & 16.5 \\
\hline Sound Duration T (sec) & 0.9 & 0.49 & 0.7 & 0.33 & 1.6 & 0.32 & 1.8 & 0.51 & 1.5 & 0.44 \\
\hline Pulse Repetition Rate PRR (Hz) & 78 & 12.1 & 81 & 8.3 & 39 & 6.6 & 56 & 4.4 & 97 & 8.7 \\
\hline
\end{tabular}


frequency of females is higher than that of males.

Accordingly, the relationship between each acoustic parameter and body length confirmed the roaring individual (Fig. 6). The parameters $F_{0}, F_{1}$, and PRR were all inversely proportional to body size. The body length distribution of the wild sea lions, which could not be measured, was estimated from the distribution of $F_{1}$ using the regression equation with the highest correlation coefficient between $F_{1}$ and body length in captive sea lions:

$$
\begin{aligned}
F_{1}(H z)= & 42.57 \text { Body length }(m)+ \\
& 1103.1\left(R^{2}=0.8359\right)
\end{aligned}
$$

The distributions of the body lengths of wild sea
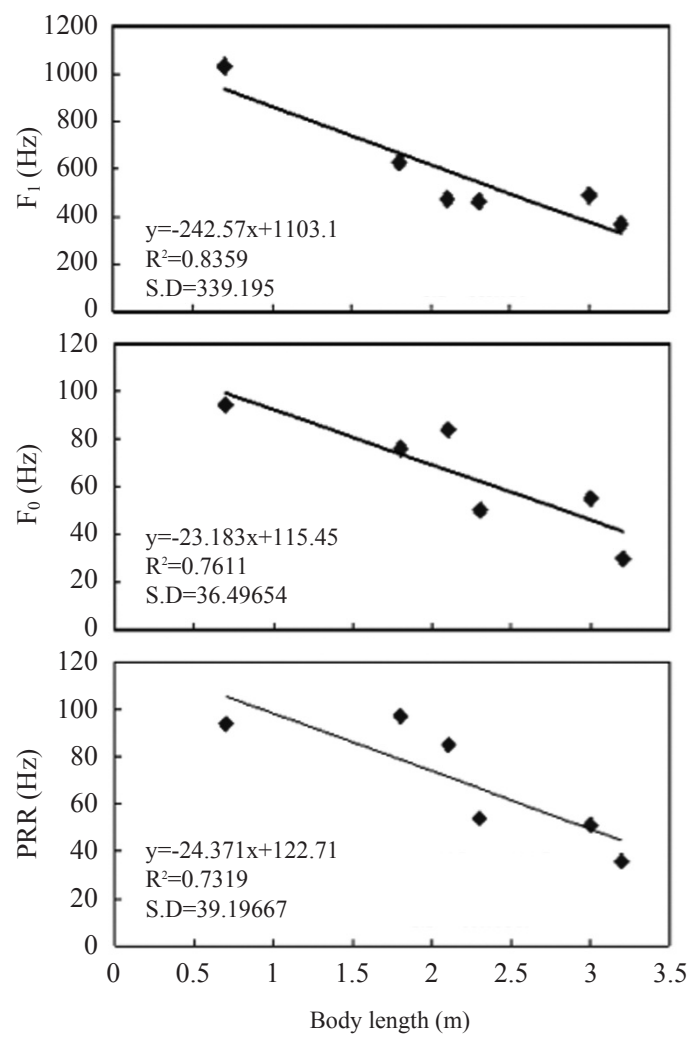

Fig. 6. Relationship between acoustic parameters of roars and body length in captive sea lions.

The highest significant linear relationship between body length and formant frequency $\left(\mathrm{F}_{1}\right)$ was found. lions, estimated using the formant frequency distribution and from bird's-eye photographs using a distance marker drawn on the reef, are shown in Fig 7. We found similar bi-modal patterns in both graphs and the principal modes of both graphs were similar. The small mode of the histogram $(-1.5 \mathrm{~m})$ was due to juveniles; the principal mode $(-2 \mathrm{~m})$ was adult females; and the components larger than $2.5 \mathrm{~m}$ were adult males. However, it is debatable whether the body length dependence of the roar of captive sea lions was equivalent to that of wild sea lions, and whether there were no biases in roaring frequency for sex and growth stage. Further observations of the roars of identified individuals are necessary.

These results lead to the conclusion that 1) The roars of Steller sea lions are characterized by their fundamental frequency $\left(\mathrm{F}_{0}\right)$, formant frequency $\left(\mathrm{F}_{1}\right)$, duration $(\mathrm{T})$, and pulse repetition rate (PRR). 2) $F_{0}, F_{1}$, and PRR of the roars of wild sea lions were higher than those of captive sea lions, and they increased in the order adult males, adult

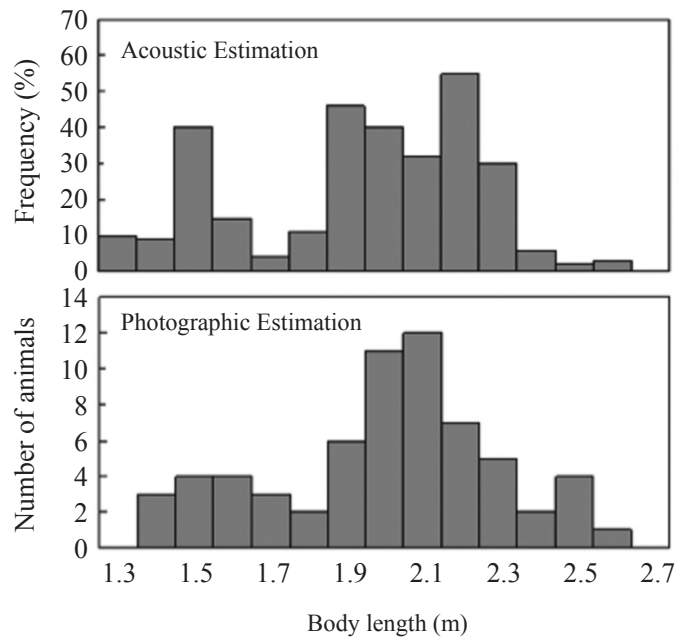

Fig. 7. Comparison of the body length distributions of wild sea lions on the reef estimated by the acoustic estimation and the photographic estimation. 
females, and juveniles. 3) $F_{0}, F_{1}$, and PRR were inversely proportional to body length. 4) The body length distribution estimated using roar sound statistics roughly agreed with estimates from a photographic analysis.

\section{Acknowledgments}

The authors thank Emeritus Professor Haruo Ogi of Hokkaido University, who motivated us to begin this research. We also thank Mr. Shoji Kotani and Mr. Takuma Takayama for their assistance with the experiments and in collecting material. Thanks are also due to Dr. John K. Horne for reading the manuscript and making a number of helpful suggestions.

\section{References}

Evance, W.E., 1966. Vocalization among marine mammals. In: W.N. Tavolga (ed.), Marine bioacoustics. Pergamon Press, London, pp.159-186.

Hobson, E.S., 1966. Visual orientation and feeding in seals and sea lions. Nature, 210, 326-327.

Iida, K., T.G. Park, T. Mukai and S. Kotani, 2006. Avoidance of Artificial Stimuli by the Steller Sea Lion, Sea Lion of the World. Alaska Sea Grant College Program, AK-SG-06-01, 535-548.
Kelemen, G., 1963. Comparative anatomy and performance of the vocal organ in vertebrates. In: R.G. Busnel (ed.), Acoustic behaviour of animals. Elsevier Publishing Company, Amsterdam, pp. 489 -521 .

Oliver, G.W., 1978. Navigation in mazes by a grey seal, Halichoerus grypus (Fabricius). Behaviour 67, $97-$ 114.

Park, T.G., K. Iida and T. Mukai, 2006. Characteristics of Vocalizations in Steller Sea Lions, Sea Lion of the World. Alaska Sea Grant College Program, AK-SG06-01, 549-560.

Schustreman R.J., 1972. Visual acuity in pinnipeds. In H.E. Winn and B.L. Olla (eds.), Behavior of marine animals. Plenum Press, New York, pp. 469-492.

Schustreman, R.J., D. Kastak, D.H. Levenson, C.J. Reichmuth and B.L. Southall, 2000. Why pinnipeds don't echolocate. J. Acoust. Soc. Am., 107, $2256-$ 2264.

Scronce, B.L. and S.H. Ridgway, 1980. Gray seal, Halichoerus grypusa: Echolocation not demonstrated. In R.G. Busnel and J.F. Fish (eds.), Animal Sonar System, Plenum Press, New York, pp. 991 - 993.

2010년 10월 28일 접수

2010년 11월 10일 1차 수정

2010년 11월 11일 수리 